\title{
A tormentor in the quest for plant p53-like proteins
}

\author{
Henrie A.A.J. Korthout*, Martien P.M. Caspers, Marijke J. Kottenhagen, Quinta Helmer, \\ Mei Wang
}

Center for Phytotechnology TNO/UL, Wassenaarseweg 64, 2333 AL Leiden, The Netherlands

Received 10 June 2002; revised 17 July 2002; accepted 17 July 2002

First published online 29 July 2002

Edited by Ulf-Ingo Flügge

\begin{abstract}
Over the past few years the presence of p53-like proteins in plants was frequently reported, by using the monoclonal antibody Pab240. By means of protein purification and screening a cDNA library, a Pab240 cross-reacting protein and a cDNA clone were isolated from barley. Peptide- and DNAsequence analysis identified one and the same protein: 2-oxoglutarate dehydrogenase. Sequence analysis of 2-oxoglutarate dehydrogenase revealed that the protein contains a perfect Pab240 epitope. In barley, the 110 kDa oxoglutarate dehydrogenase was degraded during isolation to a $53 \mathrm{kDa}$ Pab240 cross-reacting polypeptide, thereby mimicking curiously p53like properties. (C) 2002 Federation of European Biochemical Societies. Published by Elsevier Science B.V. All rights reserved.
\end{abstract}

Key words: 2-Oxoglutarate dehydrogenase; p53; Pab240; Immuno recognition; Barley

\section{Introduction}

Since the first reports that a mechanism of programmed cell death (PCD) occurs in animal as well as in plant cells, research has been focussed on whether typical pathways leading to PCD are conserved among these two kingdoms. Although the majority of the key proteins involved in PCD pathways are highly conserved in animal cells, only a very limited number of counterparts were identified in plants thus far, based on sequence homology. One of the key regulatory proteins of the mammalian apoptotic machinery is tumour suppressor p53. In mammals it is known that p53 mediates G1 arrest following DNA damage in order to allow DNA repair or, in case of severe DNA damage, to induce apoptosis (recently reviewed by Bargonetti and Manfredi [1]). This dual role makes p53 the guardian of the genome integrity. In spite of the fact that several homologues of animal proto-oncogene and tumour suppressor gene-related proteins, like $c-m y c, c$-fos and $c$-jun, as well as cell cycle regulatory proteins, like retinoblastoma, were identified in plants [2], a putative plant p53 is still not identified. However, several reports appeared in the past ten years speculating on the presence of a putative p53 in plant cells. By using the monoclonal antibody Pab240, recognising a

\footnotetext{
*Corresponding author. Fax: (31)-71-5274863.

E-mail addresses: korthout@voeding.tno.nl (H.A.A.J. Korthout), caspers@voeding.tno.nl (M.P.M. Caspers), kottenhagen@voeding.tno.nl (M.J. Kottenhagen), helmer@rulbim.leidenuniv.nl

(Q. Helmer),wang@voeding.tno.nl (M. Wang)
}

five amino acid stretch in the central core of the murine p53, cross-reactivity with polypeptides in the range of $53-100 \mathrm{kDa}$ has been found in Zea mays [3,4] and Pisum sativum [5,6]. The presence and intensity of these cross-reactive bands were often correlated with DNA repair, especially during seed germination [3-7]. Such a correlation is quite conceivable since it has been established that aged seeds contain high levels of DNA damage, occurring during storage of seeds [8] and aged seeds do have an increased mean germination time relative to their unaged counterparts, probably due to an extension of the G1 phase to allow DNA repair [7]. So if it is a question of the presence of a plant p53 homologue, indeed one expects to find it in this stage of plant development.

In our previous experiments, cross-reactivity with 53, 73 and $110 \mathrm{kDa}$ polypeptides with the Pab240 antibody were found in barley suspension cells as well as in germinating barley seeds (unpublished data). In concert with the results reported from pea and maize [3-6] the intensity of the immunostained bands was increased dramatically during the early stage of germination but also after exposure of the suspension cells to UV-B radiation. In this study these cross-reactive polypeptides were identified from protein purification as well as from isolation of cross-reacting clones from a barley cDNA expression library. Both approaches reveal that the cross-reacting polypeptides are not putative plant p53 homologues but 2-oxoglutarate dehydrogenase, a complex-forming enzyme involved in the Krebs cycle but containing an ideal epitope to be recognised by the Pab240 antibody.

\section{Materials and methods}

\subsection{Plant material}

Embryonic cell suspensions were from barley (Hordeum vulgare $\mathrm{L}$. cv. Igri) immature in vivo embryo-derived callus (12 days after flowering) as described by Korthout et al. [9].

\subsection{Protein purification}

About $900 \mathrm{~g}$ fresh-weight embryonic suspension cells were harvested by filtration over one layer Whatman paper no. 1. The cells were homogenised in a buffer (100 ml for each $100 \mathrm{~g}$ cells) containing

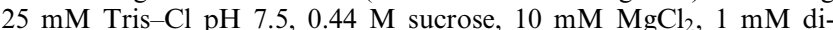
thiothreitol (DTT), $0.1 \%(\mathrm{w} / \mathrm{v})$ Triton X-100 and $0.1 \mathrm{mM}$ phenylmethylsulfonyl fluoride (PMSF) using an Ultrathurrax (Janke and Kunkel, Staufen, Germany; three pulses at $24000 \mathrm{rpm}$ of $30 \mathrm{~s}$ intervals). The homogenate was filtrated over two layers of cheesecloth and subsequently centrifuged for $5 \mathrm{~min}$ at $600 \times g$ to obtain the cellular debris and $20 \mathrm{~min}$ at $50000 \times \mathrm{g}$ to obtain the cytosolic extract. Hence, Pab240 reactive protein(s) were isolated from the cytosolic extract by a three-step purification protocol. The first step consists of ammonium sulphate precipitation. All Pab240 reactive proteins precipitate $55-65 \%$ of saturated ammonium sulphate. After dialysis $\left(\mathrm{o} / \mathrm{n}\right.$ at $4^{\circ} \mathrm{C}$ against a buffer containing $25 \mathrm{mM}$ Tris- $\mathrm{Cl} \mathrm{pH} 7.5,1 \mathrm{mM}$ DTT and $0.1 \mathrm{mM}$ PMSF, using Spectra/por $25 \mathrm{~mm}$ cellulose dialyse tubing; 
m.w. cut-off 12000-14000; Spectrum Medical Industries, Los Angeles, CA, USA) the dialysate was loaded on a $6 \mathrm{ml}$ Resource-Q column connected to a FPLC-system (Amersham Biosciences, Uppsala, Sweden). Pab240 reactive proteins were eluted between 0.40 and $0.45 \mathrm{M} \mathrm{NaCl}$ in dialyse buffer. The Pab240 reactive proteins were further purified by means of preparative SDS-PAGE and fractions containing proteins with molecular masses ranging between 105 and $125 \mathrm{kDa}$ were collected. These fractions were pooled, concentrated by means of ultra-filtration (Diaflow 10YM30 ultra-filtration membranes, Amicon Corporation, Beverly, MA, USA) and dialysed against a buffer containing $25 \mathrm{mM}$ Tris $-\mathrm{Cl} \mathrm{pH} 7.5$ and $5 \mathrm{mM}$ EDTA $\left(\mathrm{o} / \mathrm{n} 4^{\circ} \mathrm{C}\right)$. Thereafter ATP was added to a final concentration of $6 \mathrm{mM}$ and the proteins were digested with trypsin $\left(20 \mu \mathrm{g} / \mathrm{ml}, 50 \mathrm{~min}, 23^{\circ} \mathrm{C}\right)$. The digest was subjected to SDS-PAGE and the 73 and $53 \mathrm{kDa}$ polypeptide Pab240 cross-reacting bands excised from gel and used for sequence analysis.

\subsection{Screening of barley expression library with Pab240}

An expression cDNA library was constructed by using $\lambda \mathrm{ZAP} E x-$ press ${ }^{\circledR}$ vectors according to the manufacturer's instructions (Stratagene, La Jolla, CA, USA). Total mRNA was isolated from a mixture of heat-shocked $\left(30 \mathrm{~min}, 42^{\circ} \mathrm{C}, 24 \mathrm{~h}\right.$ recovery) and control barley embryonic suspension cells. The mRNA was converted to cDNA and packed into XZAP Express ${ }^{\circledR}$ vectors. The vectors were tested on the presence of multiple-sized inserts. The average size was about $0.5-2 \mathrm{kbp}$.

Immunological screening of the expression library with Pab240 was performed as described by Sambrook et al. [10], starting with twelve $150 \mathrm{~mm}$ plates containing approximately 50000 plaque forming units each. About 50-100 positive clones per plate were obtained after the first screen. After purification and isolation of Pab240 immuno-reactive $\lambda$-clones, the pBKCMV vectors containing the inserts were excised from the $\lambda$-clones according to the manufacturer's instructions and subjected to sequence analysis.

\subsection{Electrophoretic separation and Western blot analysis}

Samples for protein analysis were separated on a $10 \%$ SDS-PAGE gel according to Laemmli [11]. The proteins were electro-transferred to a nitrocellulose membrane (Schleicher and Schuell). For Western analysis the monoclonal antibody Pab240 (sc-99, Santa Cruz Biotechnology, Santa Cruz, CA, USA) was used. Visualisation was performed with goat-anti-mouse horseradish peroxidase (HRP) conjugate (Promega, Madison, WI, USA) followed by chemoluminescent detection.

Preparative electrophoresis was performed by using a Prep-Cell (model 491, Bio-Rad Laboratories, Hercules, CA, USA) on a $75 \mathrm{ml}$ $6 \%$ polyacrylamide gel. During the run (at $40 \mathrm{~mA} / \mathrm{h}$ ) fractions of $9 \mathrm{ml}$ were collected and analysed on SDS-PAGE and Western blotting.

\subsection{Protein sequence analysis}

Polypeptides excised from gel were digested in gel with trypsin extracted from gel and separated by means of preparative high-performance liquid chromatography (HPLC). The amino acid sequence analysis of the peptides was performed by means of N-terminal protein sequence analysis by using an Applied Biosystems Model 494 Procise Protein Sequencing System, on-line connected to an RPHPLC unit for identification of the step-wise released PTH amino acids.

Sequence analysis was performed by Eurosequence (Groningen, The Netherlands).

\section{Results}

For studying the presence of p53-like proteins in plant cells, several antibodies were used. Among them the monoclonal Pab240, an antibody originally generated in monoclonal hybridomas from a mouse immunised with a $\beta$-galactosidase/ murine-p53 fusion protein [12]. By epitope mapping it was

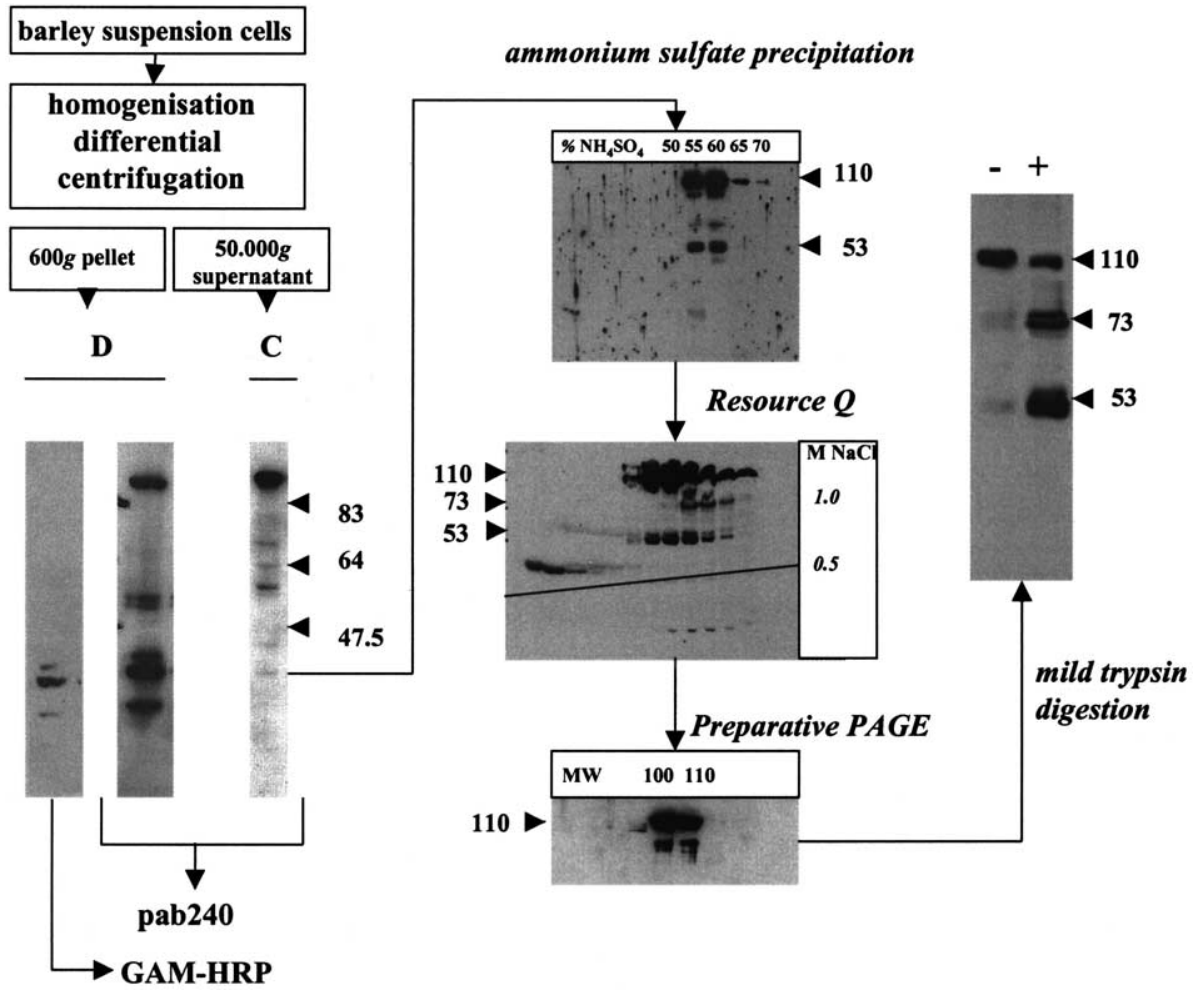

Fig. 1. Purification protocol for the isolation of the $110 \mathrm{kDa}$ Pab240 cross-reactive polypeptide from barley embryonic suspension cells. After differential centrifugation, a $600 \times g$ pellet was obtained consisting of cellular debris (D; organelles and nuclei) and a $50000 \times g$ supernatant containing the cytosolic fraction (C). The cytosolic fraction was subjected to a purification protocol comprising ammonium sulphate precipitation, anion exchange (Resource Q) and Preparative PAGE as described in Section 2. Fractions were collected and analysed on Western blots. The $110 \mathrm{kDa}$ polypeptide $(-)$ was subjected to mild trypsin digestion $(+)$ and the 73 and $53 \mathrm{kDa}$ bands were excised from gel and used for sequence analysis. The antibody utilised in all blots was Pab240. Non-specific cross-reaction caused by the secondary antibody (GAM-HRP) was found mainly to be present in the cellular debris. 


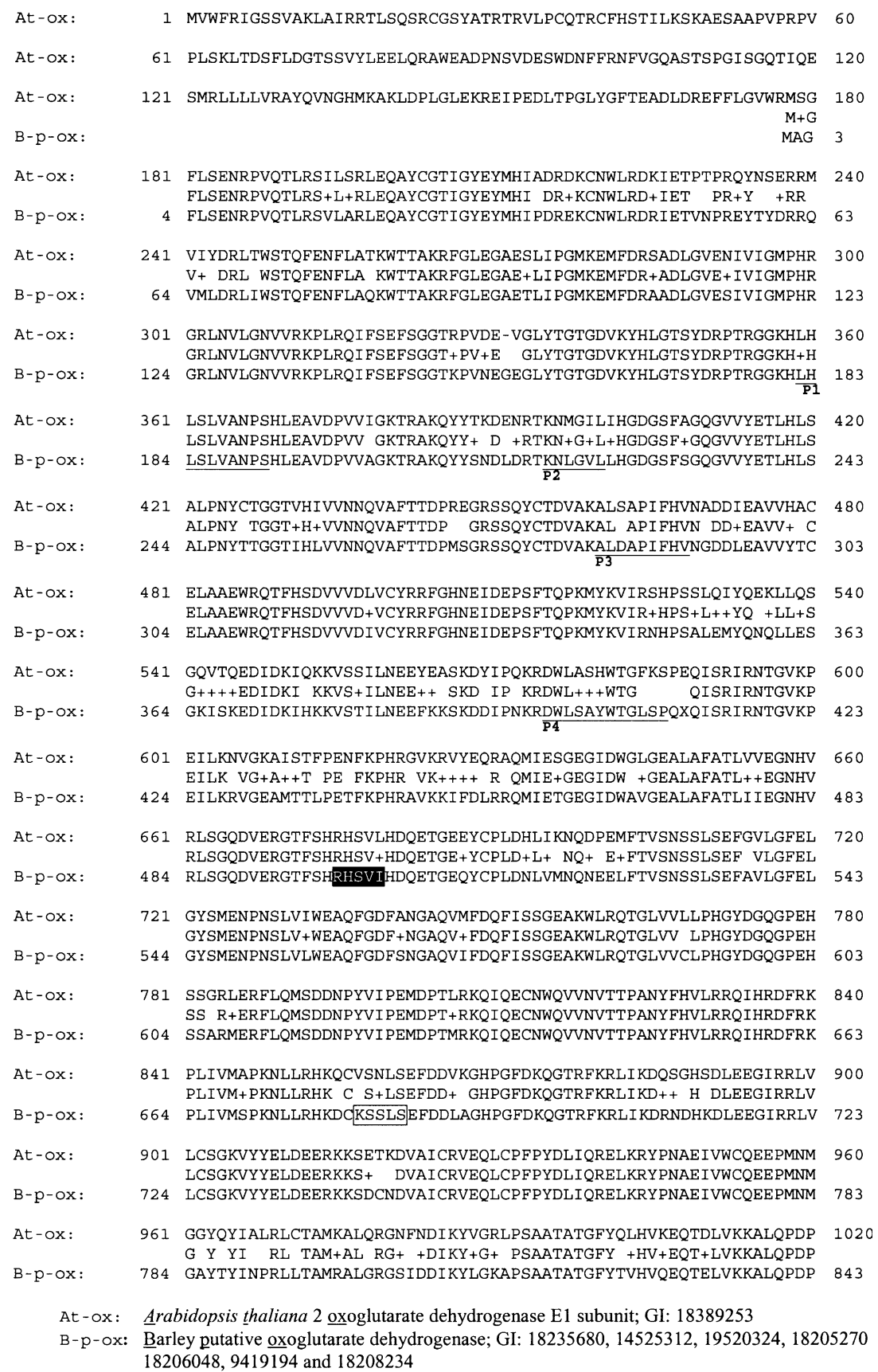

Fig. 2. Amino acid alignment between the 2-oxoglutarate dehydrogenase E1 subunit (At-ox) and the barley homologue (B-p-ox). The barley 2-oxoglutarate dehydrogenase E1 subunit homologue is a composite constructed from overlapping sequences present in the database. Sequences obtained from four tryptic digests from the $110 \mathrm{kDa}$ purified Pab240 cross-reactive polypeptide (P1-P4) were 100\% identical with the underscored sequence. Black box: Pab240 recognition site; white box: putative Pab122 recognition site.

found that this antibody recognises a five amino acid long epitope, RHSV(V/I), of human, mouse and chicken p53 [13]. In barley embryonic suspension cells, this antibody showed cross-reaction with several polypeptides ranging from 10 to $110 \mathrm{kDa}$. The cross-reaction with the small polypeptides, which were predominant in the cellular debris after centrifugation, was unspecific since cross-reaction was also observed by using only the secondary antibody GAM-HRP (Fig. 1). However, three polypeptides of 53, 73 and $110 \mathrm{kDa}$, respectively, present in the cytosolic fraction after centrifugation, specifically cross-react with the Pab240 antibody. Especially the 73 and $53 \mathrm{kDa}$ polypeptides frequently appeared on blot as doublets. The ratio between these three Pab240 cross-reactive polypeptides varied among different extracts we made. In order to find out whether these different polypeptides were related to each other and whether they represented plant p53-like proteins, a three-step purification protocol was developed as described in Section 2. The purification, as schematically depicted in Fig. 1, finally resulted in a purified $110 \mathrm{kDa}$ polypeptide from the cytosolic extract which could be converted to the 73 and $53 \mathrm{kDa}$ form by means of mild trypsin digestion. Both 73 and $53 \mathrm{kDa}$ polypeptides were subjected to sequence analysis. First by peptide mapping it became clear that the doublets represent one and the same protein. Se- 
quence analysis resulted in the identification of four peptides (P1-P4 in Fig. 2) which were all homologues to the Arabidopsis 2-oxoglutarate dehydrogenase. By searching for the barley homologue in the NCBI database we were able to retrieve seven expressed sequence tags which almost fully covered the entire protein (Fig. 2). Amino acid positions 498-502 of the barley composite exposes the sequence RHSVI, indeed an epitope for Pab240 [13,14]. Moreover, positions 680-684 expose a putative epitope for another p53 monoclonal antibody, Pab122.

Independently of the protein purification as described above, another approach was followed to identify the Pab240 cross-reactive protein in barley. An expression library was constructed from the total mRNA pool isolated from a mixture of heat-shocked and control barley suspension cells. First we have checked whether cross-reactivity of Pab240 occurs in Escherichia coli cells, the host cells of the $\lambda$ ZAP phages. No cross-reaction could be observed. After screening of the transfected library, several Pab240 cross-reactive clones were found and subsequently isolated. One strong cross-reactive clone was selected for sequence analysis. Again this sequence showed a strong similarity with the Arabidopsis 2-oxoglutarate dehydrogenase (Fig. 3). These data confirm the identity of the Pab240 cross-reactive protein in barley as obtained by protein purification.

Next we wanted to find out whether the 53, 73, both often appearing as a doublet, and $110 \mathrm{kDa}$ polypeptides were related to each other or different proteins carrying an epitope for Pab240. It was shown that mammalian p53s exposing the pab240 epitope are able to associate with heat-shock protein hsp70 [12]. If we heat-shocked our barley cell suspensions (10 $\min 42^{\circ} \mathrm{C}$ ) at several time points prior to protein extraction we could clearly demonstrate that both the 53 and $73 \mathrm{kDa}$ crossreactive bands disappear in favour of the $110 \mathrm{kDa}$ band (Fig. 4). Moreover, if the heat-shocked sample containing the 110 $\mathrm{kDa}$ protein (or the $110 \mathrm{kDa}$ protein isolated by preparative PAGE during the purification protocol) was treated with a low concentration of trypsin, the intensity of the $110 \mathrm{kDa}$ band diminished and the 73 and $53 \mathrm{kDa}$ bands appeared again on Western blot. The concentration of trypsin used in

$$
\begin{aligned}
& \begin{array}{c}
\text { PRC : } 509 \text { tcttgggtttgaattgggctactccatggagaacccaaattcgctagtactctgggaagc } \\
\text { At-ox: } 2260 \text { tctcggtttcgaactgggttattcgatggaaaatcccaattctctggtgatatgggaagc } \\
\text { At }
\end{array} \\
& \text { PRC : } 569 \text { tcagtttggtgactgccccaatggtagcacaagtgatgttcgaccatctactgagtagag }
\end{aligned}
$$

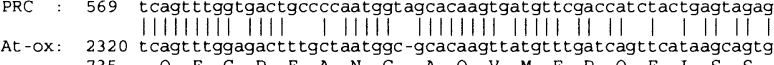

$$
\begin{aligned}
& \text { At-ox: } 7320 \text { tcagtteggagactt tgct aatggc-gcacaagttatgtetgatcagttcataagcagtg } \\
& \text { PRC : } 629 \text { gagatgcaaaatggctgcg-catactggccttgttgttctactgcctcatggttatgatg }
\end{aligned}
$$

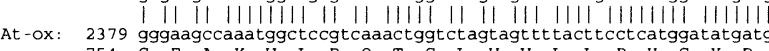

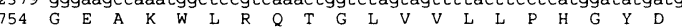

$$
\begin{aligned}
& \text { PRC : } 688 \text { gtcaaggtcctgaacactccagctcctttttaggatcgcttgcttgagatgagtgatgac }
\end{aligned}
$$

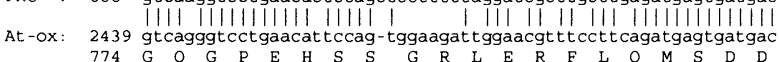

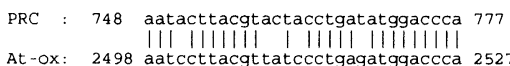

$$
\begin{aligned}
& \begin{array}{l}
2498 \text { aatccttacgttatccetgagatggaccca } \\
794 \text { N P Y V I P E M D P }
\end{array}
\end{aligned}
$$

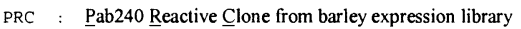

$$
\begin{aligned}
& \text { At-ox: Árabidopsis thaliana } 2 \text { oxoglutarate dehydrogenase E1 subunit; GI: } 18389253
\end{aligned}
$$

Fig. 3. Nucleotide sequence alignment between a clone isolated from the barley expression library, cross-reacting with the Pab240 antibody (PRC), and the 2-oxoglutarate dehydrogenase E1 subunit from Arabidopsis thaliana (At-ox). $81 \%$ identity was obtained.

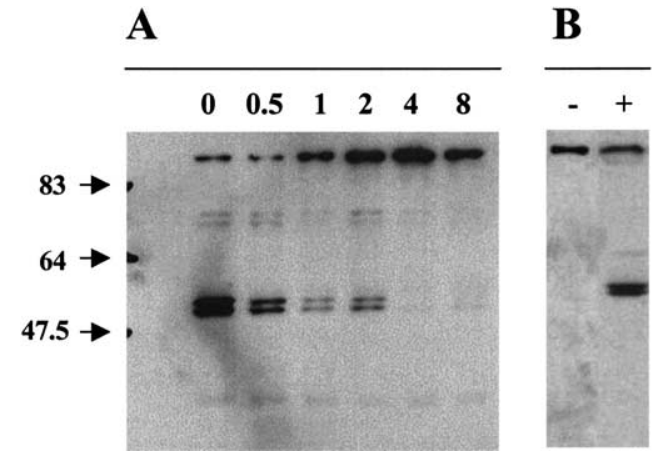

Fig. 4. A: Behaviour of the Pab240 cross-reactive polypeptides in cytosolic extracts of barley embryonic suspension cells after heat shock $\left(10 \mathrm{~min}, 42^{\circ} \mathrm{C}\right)$. Cytosolic extracts were made prior to heat shock $(0)$ and after $0.5,1,2,4$ and $8 \mathrm{~h}$ recovery at $28^{\circ} \mathrm{C}$. B: Trypsin treatment of a cytosolic extract obtained from heat-shocked cells after $4 \mathrm{~h}$ recovery; (-) before trypsin treatment, (+) after $50 \mathrm{~min}$ incubation with $20 \mu \mathrm{g} / \mathrm{ml}$ trypsin at $23^{\circ} \mathrm{C}$. Both Western blots were probed with the Pab240 antibody.

these experiments was extremely critical since a small increase resulted in complete disappearance from the blot. These data strongly indicate that the 53 and $73 \mathrm{kDa}$ polypeptides were degradation products of the $110 \mathrm{kDa}$ polypeptide due to proteolytic activity during isolation. We suggest that binding of heat-shock proteins to the $110 \mathrm{kDa}$ polypeptide in reaction to heat shock (Fig. 4A) may prevent this degradation. The fact that tryptic digests of the $53 / 73 \mathrm{kDa}$ polypeptides, obtained during sequence analysis, display a high degree of homology with the $105 \mathrm{kDa} 2$-oxoglutarate dehydrogenase strongly supports this hypothesis.

\section{Discussion}

In this study we have demonstrated that the cross-reactivity with the p53-specific Pab240 antibody in barley was not caused by a putative plant p53 homologue but by 2-oxoglutarate dehydrogenase, a $105 \mathrm{kDa}$ subunit from a multi-enzyme assembly that occupies a central role in cellular metabolism within the tricarboxylic acid cycle. The presence of this protein combined with its biochemical features during experimental conditions causes a big obstacle for identifying p53like proteins in plants by using Western blot techniques only. It mimics the features of the mammal p53 in several ways:

First, there is a clear recognition of the plant 2-oxoglutarate dehydrogenase by one of the best studied and frequently utilised antibodies in mammalian p53 research activities, the monoclonal Pab240. Obviously, this antibody may not be specific enough, since only a small motif of five amino acid residues, RHSV(V/I), also present at positions 498-502 of the barley 2-oxoglutarate dehydrogenase composite, allows recognition by the antibody $[13,14]$. It was already demonstrated that proteins containing this motif, like TFIIIA from Xenopus leavis, cross-react with the Pab240 [13]. Referring to Stephen et al. [14], a second interesting motif may be present on the barley 2-oxoglutarate dehydrogenase composite, KSSLS, located at positions 681-685, which mimics an epitope for the p53 monoclonal Pab122 [14]. Interestingly, in pea root tips a $94 \mathrm{kDa}$ protein was recognised by both Pab240 and Pab122 antibodies [5]. However, due to limited information on the Pab122 epitope, the lack of sequence information of the pea oxoglutarate dehydrogenase homologue and the fact that dif- 
ferent experimental procedures were used as compared to our study, it is not possible to predict whether cross-reactivity in pea is also caused by oxoglutarate dehydrogenase.

Second, we observed a dramatic increase in intensity of the Pab240 cross-reactive bands during the early stage of germination. In this period the machinery of DNA repair, to recover DNA integrity induced during seed maturation and storage $[7,8]$, is fully operable. In mammalian cells p53 induces G1 arrest to allow DNA repair, so indeed one expects to find an increase of the putative plant p53 during early germination. On the other hand, during early germination also the plant cellular metabolism is fully switched on, e.g. enzymatic activity in the tricarboxylic acid cycle. Consequently, it remains unclear whether the observed increase of the Pab240 cross-reactive bands during the early stage of germination is a result of an increase of p53-related proteins involved in DNA repair or just an increase of the metabolic enzyme oxoglutarate dehydrogenase.

Third, the molecular weight of the Pab240 cross-reactive proteins in plant extracts under denaturing conditions is similar to that of mammalian p53. However, next to a $53 \mathrm{kDa}$ band, a 73 and $110 \mathrm{kDa}$ band were also recognised in barley extracts by the Pab240 antibody. Interestingly, the ratio of the intensity of those 53,73 and $110 \mathrm{kDa}$ bands varied within the several extracts we made. Cross-reactivity in the region of 70 and $100 \mathrm{kDa}$ by the Pab240 antibody was already reported to occur in maize [3] and pea [5,6]. In this report we showed that in our experimental system, the cytosolic extract of barley suspension cells, the 53, 73 and $110 \mathrm{kDa}$ bands are related to each other. Artificial proteolytic cleavage of the purified $110 \mathrm{kDa}$ band by controlled trypsin digestion revealed that the $110 \mathrm{kDa}$ band could be easily converted to the 73 and 53 $\mathrm{kDa}$ form. Moreover, with heat-shock treatment of the barley suspension cells we showed that the intensity of the $53 / 73 \mathrm{kDa}$ bands isolated during extraction decreased dramatically in favour of the $110 \mathrm{kDa}$ band. Furthermore, it was shown by Gannon et al. [12] that proteins exposing the Pab240 epitope RHSV(V/I) were able to bind heat-shock protein hsp70. These chaperones are highly conserved proteins among the animal and plant kingdom. Assuming that 2-oxoglutarate dehydrogenase exposes its RHSVI motif, the hsp70, probably present in a chaperone complex, may associate and consequently stabilise the protein, thereby preventing proteolytic cleavage during isolation, especially after heat shock. It may be interesting to note that during purification of the $110 \mathrm{kDa}$ polypeptide the heat-shock protein hsp82, a member of the hsp90 family, was co-purified (data not shown). It is known that chaperone complexes may contain both hsp90 and hsp70 proteins and that these complexes are evolutionarily conserved between the animal and plant kingdom [15]. Taken together, there are strong indications that the 53, 73 and $110 \mathrm{kDa}$ polypeptides represent one and the same protein, the $105 \mathrm{kDa} 2$-oxoglutarate dehydrogenase.

The fact that the Pab240 cross-reactive protein(s), obtained by protein purification as well as by screening of an expression library, was identified as 2-oxoglutarate dehydrogenase, does not exclude the possibility that more Pab240 cross-reacting proteins or even p53-related proteins exist in plant cells. For example, 2-oxoglutarate dehydrogenase is a metabolic protein present in a complex in the mitochondria, but in pea cross- reactivity with the Pab240 was also observed in nuclei by means of immuno-localisation studies [5]. However, extreme caution must be taken by interpretation of data only obtained by immunological experiments. In our opinion, the putative plant $\mathrm{p} 53$, if it exists, will be a functional homologue rather than a structural one. Searching for sequence homology in plant nucleotide databases failed thus far and moreover, even among animals the p53 protein is not highly conserved. Only recently the p53 homologues of Drosophila melanogaster [16-18] and Caenorhabditis elegans [19] were identified. From these studies it became clear that only a set of five domains of the p53 were conserved. The p53 homologue of $C$. elegans could not be retrieved from public databases using standard searches and only with additional algorithms the conserved domains and therefore the p53 homologue could be identified [19]. Still, even by using these conserved domains and the additional algorithms for searching in plant databases, a plant p53 homologue could not be found. Focussing on p53's interacting partners, like the highly conserved proteins involved in cell-cycle regulation or inhibitory proteins might be a fruitful strategy for identifying the plant p53 homologue.

Acknowledgements: This work was partially supported by Aventis Research and Technologies GmbH and Co KG, Germany. Thanks to $\mathrm{P}$. Wagner for stimulating discussions.

\section{References}

[1] Bargonetti, J. and Manfredi, J.J. (2002) Curr. Opin. Oncol. 14, $86-91$.

[2] Loidl, A. and Loidl, P. (1996) Crit. Rev. Oncogen. 7, 49-64.

[3] Georgieva, E.I., López-Rodas, G. and Loidl, P. (1994) Planta $192,125-129$

[4] Cruz-Garcia, F., Zúñiga-Aguilar, J. and Vázquez-Ramos, J.M. (1998) Physiol. Plantarum 102, 573-581.

[5] Onelli, E., Citterio, S., Labra, M., Ghiani, A. and Sgorbati, S. (2000) Plant Biosyst. 134, 153-165.

[6] Klosterman, S.J., Choi, J.J. and Hadwiger, L.A. (2000) Physiol. Mol. Plant Path. 56, 197-206.

[7] Whittle, C-A., Beardmore, T. and Johnston, M.O. (2001) Trends Pharmacol. Sci. 6, 248-251.

[8] Cheah, K.S.E. and Osborne, D.J. (1978) Nature 272, 593-599.

[9] Korthout, H.A.A.J., Berecki, G., Bruin, W., van Duijn, B. and Wang, M. (2000) FEBS Lett. 475, 139-144.

[10] Sambrook, J., Fritsch, E.F., Maniatis, T. (1989) Molecular Cloning: A Laboratory Manual, 2nd edn., Cold Spring Harbor Laboratory, Cold Spring Harbor, NY.

[11] Laemmli, U.K. (1970) Nature 227, 680-685.

[12] Gannon, J.V., Greaves, R., Iggo, R. and Lane, D.P. (1990) EMBO J. 9, 1595-1602.

[13] Stephen, C.W. and Lane, D.P. (1992) J. Mol. Biol. 225, 577-583.

[14] Stephen, C.W., Helminen, P. and Lane, D.P. (1995) J. Mol. Biol. $248,58-78$

[15] Stancato, L.F., Hutchison, K.A., Krisha, P. and Pratt, W.B. (1996) Biochemistry 35, 554-561.

[16] Brodsky, M.H., Nordstrom, W., Tsang, G., Kwan, E., Rubin, G.M. and Abrams, J.M. (2000) Cell 101, 103-113.

[17] Ollmann, M., Young, L.M., Di Como, C.J., Karim, F., Belvin, M., Robertson, S., Whittaker, K., Demsky, M., Fisher, W.W., Buchman, A., Duyk, G., Friedman, L., Prives, C. and Kopczynski, C. (2000) Cell 101, 91-101.

[18] Jin, S., Martinek, S., Joo, W.S., Wortman, J.R., Mirkovic, N., Sali, A., Yandell, M.D., Pavletich, N.P., Young, M.W. and Levine, A.J. (2000) Proc. Natl. Acad. Sci. USA 97, 7301-7306.

[19] Derry, W.B., Putzke, A. and Rothman, J.H. (2001) Science 294, 591-595. 